\title{
Oligosaccharide production from preserved yuzu juice using Lactobacillus sakei NY 518 and its prebiotic function
}

\author{
Sae Hyun JEON ${ }^{1}$, Duk-Hyun KIM², Shakti Chandra MONDAL ${ }^{3}$, Kwang-Yeol YANG ${ }^{4}$, Hana JEONG ${ }^{1}$, Bo-Bae LEE \\ Seung-Hee NAM ${ }^{1 *}$
}

\begin{abstract}
This study focused on the physiochemical characteristics of the oligosaccharide produced in preserved yuzu by NY 518 and its functions based on the intestinal health through antimicrobial activities. NY 518 was identified as Lactobacillus sakei. The oligosaccharide produced by L. sakei NY 518 was gluco-oligosaccharide. The oligosaccharide from preserved yuzu (OY) was found to have lower degree of polymerization than the oligosaccharide from sucrose (OS) owing to the presence of tri- to nona-saccharides. These oligosaccharides had lower $\mathrm{pH}$ and increased acidity, soluble solids, and viscosity than their substrates. OY had $67 \%$-glucosidase inhibition activity of OS and higher antibacterial effects on food-poisoning bacteria than OS. These results indicate that the oligosaccharide produced by L. sakei NY 518 in sugar-preserved foods exhibits beneficial functions (antidiabetic and antibacterial activities) and could be a good substitute for sugar.
\end{abstract}

Keywords: Lactobacillus sakei; preserved yuzu; Oligosaccharide; physiochemical properties; antibacterial activity.

Practical Application: These data could be valuable information for the practical use of functional oligosaccharide as substitute for sugar.

\section{Introduction}

Sugar accounts for about $85 \%$ of the global sweetener market. The negative impact of sugar on human health has been well reflected (Azevedo et al., 2004). Chronic diseases such as obesity and diabetes are closely related to bad eating habits, excessive sugar intake being one of them (Park et al., 2016). In response to concerns over diseases arising from high sugar intake, the World Health Organization (WHO) has recommended lowering the daily intake of sugar from 50 to $25 \mathrm{~g}$. Policies are actively under discussion to reduce intake of various sugars, especially in developed countries (Kim et al., 2016) with the increase of prebiotic production (Gibson et al., 2017). This social awareness has increased the interest in sugar-reducing and low-calorie foods among consumers, and sweeteners with various functionalities have been developed. In particular, the interest in oligosaccharides is growing. Oligosaccharides are carbohydrates that combine 2 to 10 monosaccharides, have low-calorie value but high sweetness, and improve intestinal functions (Huh, 1995).

Yuzu (Citrus junos) mainly grown in North Asia is known to contain a large amount of flavonoid ingredients such as vitamin C, hesperidin, and limonene (Yu et al., 2011). These flavonoids are known to exert excellent anti-inflammatory, antioxidant, and radical-scavenging functions (Formagio et al., 2013). Yuzu is mainly consumed as tea containing sugar-preserved yuzu peel and pulp (Kim et al., 2010). Sugar-preserved food or jam such as sugar-preserved yuzu is manufactured by adding excess sugar. Various studies have been conducted to replace the excess sugar with oligosaccharides (Jung et al., 2017; Bae \& Yoo, 2019). However, oligosaccharides produces from yuzu might be used as prebiotic since some bacteria such as Lactobacillus and /or Bifidobacterium spp. may use these substrate selectively for health benefits (Gibson et al., 2017) with good antioxidant activity (Chen et al., 2019; Liu \& Li, 2020; Zhao et al., 2019).

To date, studies have only replaced sugar with oligosaccharides in sugar-preserved food instead of converting it into oligosaccharides through microbial enzymes. There are a few published reports on the bioconversion of sugars into oligosaccharides using microorganisms.

In this study, the sugar from preserved yuzu was converted into an oligosaccharide by Lactobacillus sakei NY 518, and the functionalities ( $\alpha$-glucosidase inhibition and antimicrobial activity) of the oligosaccharides from sucrose and preserved yuzu were compared.

\section{Materials and methods}

\subsection{Reagents and materials}

The traditional foods used in this experiment, such as soybean paste, red pepper paste, kimchi, and makgeolli, were 
collected from various parts of South Jeolla Province in Korea. The preserved yuzu (EDEN Co., Ltd., Goheung, Jeolla Province, Korea) used in this experiment was purchased from a local market. The supernatant of cultured medium excluding precipitates was used in the enzyme reaction. Reagents used in the analysis were purchased from Sigma-Aldrich Co. (St Louis, MO, USA).

\subsection{Isolation of lactic acid bacteria}

After mixing $20 \mathrm{~g}$ of the collected specimen with $80 \mathrm{~mL}$ of $0.85 \%$ (w/v) sterile normal saline, the sample was spread on De Man, Rogosa, and Sharpe (MRS) agar (Difco, Sparks, MD, USA), Luria Bertani (LB) agar (Difco), and yeast malt (YM) agar plates and incubated for 48 to $96 \mathrm{~h}$ at $37^{\circ} \mathrm{C}$. After culturing, potential lactic acid bacterium colonies were picked. In total, 519 colonies were selected, sub-cultured thrice, and cultivated in MRS broth for experimental use.

\subsection{Screening for lactic acid bacteria that produce oligosaccharides}

MRS broth containing each bacterial strain $(10 \mu \mathrm{L})$ which shown an optical density of 0.5 at $600 \mathrm{~nm}$ wavelength smeared on MRS, LB, and YM agar plates containing 10\% sucrose. After cultivation at $37^{\circ} \mathrm{C}$ for $20 \mathrm{~h}$, the degree of mucus formation was evaluated. In total, 36 strains with excellent viscosity were selected based on amount of mucus ' $0 \mathrm{mM}$ ' (-), 'on the periphery of strains' $(+)$, 'on the periphery of plate' $(++)$, 'the whole of plate' $(+++)$, and 'flow from plate' $(++++)$. The strains were stored at $-80{ }^{\circ} \mathrm{C}$ in MRS broth with $40 \%$ glycerol. To screen oligosaccharide-producing strains, culture media of 36 strains were subjected to thin-layer chromatography (TLC) analysis as per the method of Ghebregzabher et al. (1976) with minor modifications. Each strain was allowed to grow in MRS broth to an OD value of 2.0. The cell density was adjusted to an OD value of 0.5 , and the cells were incubated in MRS (with 2\% sucrose) broth without glucose at $28^{\circ} \mathrm{C}$ for $24 \mathrm{~h}$. Centrifugation (6200, Kubota, Tokyo, Japan) was performed for $10 \mathrm{~min}$ at 6,000 $\times$ g, and the supernatant obtained was used as enzyme solution. The reaction was carried out by mixing the enzyme solution with $0.2 \mathrm{M} \mathrm{Na}$-acetate buffer ( $\mathrm{pH}$ 5.2) and $100 \mathrm{mM}$ sucrose at $28^{\circ} \mathrm{C}$ for $24 \mathrm{~h}$. Each reactant was dropped at $1 \mu \mathrm{L}$ volume, and the plate was developed using nitromethane: 1-propanol: water $(2: 5: 1.5, \mathrm{v} / \mathrm{v} / \mathrm{v})$. After development, the TLC plate was sprayed with a reagent comprising $0.3 \% \mathrm{~N}$-(1-naphthyl) ethylenediamine dihydrochloride and $5 \%$ sulfuric acid $\left(\mathrm{H}_{2} \mathrm{SO}_{4}\right)$ in methanol and heated at $105^{\circ} \mathrm{C}$ in an oven for $6 \mathrm{~min}$.

\subsection{S rRNA gene sequencing}

After DNA extraction from cells, the $16 \mathrm{~S}$ rRNA was amplified by polymerase chain reaction (PCR) using universal primers, 27F and 1492R. The sequence of the amplified gene was identified by Macrogen Co., Ltd. using universal sequencing primers, 785F and 907R. The 16S rRNA gene sequence was compared with those in the NCBI nucleotide sequence database (http:/www. ncbi.nlm.nih.gov./blast/) by BLAST search.

\subsection{Optimum conditions for enzymatic reactions}

Each component of the previously used MRS broth was replaced with food-grade materials. The main component, meat extract, was replaced with malt extract, and $2 \%$ sucrose was added to investigate lactic acid bacterium cultivation and enzyme expression. The strains were incubated at $28^{\circ} \mathrm{C}$ for $24 \mathrm{~h}$ and then subjected to centrifugation (6200, Kubota, Tokyo, Japan) for $10 \mathrm{~min}$ at $8,000 \mathrm{rpm}$. The supernatant obtained was used as enzyme solution. To optimize the production of oligosaccharides using sucrose and preserved yuzu, the degree of oligosaccharide production was confirmed from substrate concentration, enzyme concentration, and reaction time at $28{ }^{\circ} \mathrm{C}$. The concentrations of sucrose were $0.1,0.2,0.5,1.0,2.0$, and $2.5 \mathrm{M}$, and those of preserved yuzu were $5 \%, 10 \%, 25 \%, 50 \%$, and $75 \%$. The enzyme solution was used at $1 \%, 5 \%, 7.5 \%, 10 \%$, and $20 \%$ concentrations, while the reaction was carried out either for $0,1,3,6,9,15,18$, $21,24,36,48$, or $72 \mathrm{~h}$. Oligosaccharide production was confirmed based on the content of released fructose.

\subsection{Quantitation and qualification of oligosaccharide by two-dimensional TLC}

Two-dimensional TLC was performed based on the method of Chuang et al. (2001) with slight modifications. The first solvent acetonitrile: ethylacetate: 1-propanol: water $(85: 20: 50: 50, \mathrm{v} / \mathrm{v} / \mathrm{v} / \mathrm{v})$ was used twice. After the first development step, the components were redeveloped twice with nitromethane: 1-propanol: water $(2: 5: 1.5, \mathrm{v} / \mathrm{v} / \mathrm{v})$ after rotating the TLC plate at $90^{\circ}$. The TLC plate was dried, stained with $5 \% \mathrm{H}_{2} \mathrm{SO}_{4}$ solution in methanol, and heated in an oven at $120^{\circ} \mathrm{C}$ for about $15 \mathrm{~min}$. The plate was compared with standard IMo (isomalto-oligosaccharide series) and Mo (malto-oligosaccharide series). To determine the degree of polymerization (DP) of oligosaccharide from preserved yuzu (OY), two-dimensional TLC was performed, and each spot was quantified through AlphaEaseFC 4.0.0 software (Alpha Innotech, San Leonardo, CA, USA) using Mo and IMo standards.

\subsection{Physicochemical properties}

Viscosity was measured using a viscometer (DV-2+Pro, Brookfield, Middleboro, MA, USA) with a \#5 spindle at a revolution rate of $100 \mathrm{rpm}$. Color values were measured with a color difference meter (CR-400m KONICA. MINOLTA, Japan) as follows: L, lightness variable; a, from green to blue; $\mathrm{b}$, from yellow to red; $\Delta \mathrm{E}$, total color difference. Soluble solid content was determined by a digital refractometer (Pocket refractometer PAL-1, ATAGO Co., Ltd., Tokyo, Japan), and the $\mathrm{pH}$ was analyzed by using a $\mathrm{pH}$ meter (Ion S220, METTLER TOLEDO, Columbus, USA). Acidity was measured by adding two drops of $0.1 \%$ phenolphthalein to $1 \mathrm{~g}$ of sample, which was then titrated until it turned red using $0.1 \mathrm{~N}$ sodium hydroxide $(\mathrm{NaOH})$. The amount $(\mathrm{mL})$ of $0.1 \mathrm{~N} \mathrm{NaOH}$ solution consumed was converted into citric acid equivalent.

\subsection{Total sugar and reducing sugar contents}

Total sugar content: The phenol-sulfuric acid method was performed as described in a previous study (Rao \& Pattabiraman, 1989). $50 \mu \mathrm{L}$ sample and $50 \mu \mathrm{L}$ of $5 \%(\mathrm{w} / \mathrm{v})$ phenol were slowly 
mixed for $30 \mathrm{~s}$ and treated with $250 \mu \mathrm{L} \mathrm{H}_{2} \mathrm{SO}_{4}$ at $80^{\circ} \mathrm{C}$ for $30 \mathrm{~min}$. The solution was cooled to room temperature, and its absorbance was measured at $492 \mathrm{~nm}$ using a microplate spectrophotometer (BioTek Epoch, USA). Total sugar content was calculated from a calibration curve generated using glucose as standard.

Reducing sugar content: The 2,2'-bicinchoninate method was used as previously described (Doner \& Irwin, 1992). Assay solution A comprised $2.74 \mathrm{~g}$ of sodium carbonate $\left(\mathrm{Na}_{2} \mathrm{CO}_{3}\right)$ and $1.2 \mathrm{~g}$ of sodium bicarbonate $\left(\mathrm{NaHCO}_{3}\right)$ in water $(45 \mathrm{~mL})$ and $97.1 \mathrm{mg}$ of $4,4^{\prime}$-dicarboxy-2,2'-biquinoline. The solution was prepared, and its volume was adjusted to $50 \mathrm{~mL}$ with water. Assay solution $\mathrm{B}$ was composed of $62 \mathrm{mg}$ copper sulfate pentahydrate $\left(\mathrm{CuSO}_{4} \cdot 5 \mathrm{H}_{2} \mathrm{O}\right)$ and $63 \mathrm{mg} \mathrm{L}$-serine dissolved in water $(45 \mathrm{~mL})$. The volume of the solution was then adjusted to $50 \mathrm{~mL}$. An assay reagent was prepared by mixing equal volumes of assay solutions $\mathrm{A}$ and B. For the test, $50 \mu \mathrm{L}$ of sample and $300 \mu \mathrm{L}$ assay solution were mixed and heated at $80^{\circ} \mathrm{C}$ for $35 \mathrm{~min}$. The mixture was cooled for $15 \mathrm{~min}$, and its absorbance was read at $595 \mathrm{~nm}$ using a microplate spectrophotometer (BioTek Epoch, USA). Reducing sugar content was calculated from a calibration curve developed using maltose as standard.

\subsection{Analysis of phenolic compounds by High-Performance Liquid Chromatography (HPLC)}

Agilent 1260 InfinityII LC series system (Agilent Technologies, Waldbronn, Germany) was used for HPLC analysis. A ZORBAX eclipse plus C18 column $(4.6 \times 250 \mathrm{mM}$, 5-micron, Agilent Technologies, Palo Alto, CA, USA) was used for the analysis performed as per the method of Abrahim et al. (2010) with minor modifications. $0.1 \%$ formic acid was used as solvent $\mathrm{A}$ and methanol-acetonitrile as solvent $B$ as follows: $0-4.9 \mathrm{~min}, 80 \%$ $\mathrm{A}$ and $20 \% \mathrm{~B} ; 5-10 \mathrm{~min}, 60 \% \mathrm{~A}$ and $40 \% \mathrm{~B} ; 10.1-15 \mathrm{~min}, 50 \% \mathrm{~A}$ and $50 \% \mathrm{~B} ; 15.1-20 \mathrm{~min}, 30 \% \mathrm{~A}$ and $70 \% \mathrm{~B} ; 20.1-25 \mathrm{~min}, 0 \% \mathrm{~A}$ and $100 \% \mathrm{~B} ; 25.1-30 \mathrm{~min}, 80 \% \mathrm{~A}$ and $20 \% \mathrm{~B}$. The solvent flow rate was $0.5 \mathrm{~mL} / \mathrm{min}$, and the column temperature was $35^{\circ} \mathrm{C}$. The specimen $(10 \mu \mathrm{L})$ was injected, and detection was carried out at a wavelength of $280 \mathrm{~nm}$.

\section{$2.10 \alpha$-Glucosidase inhibition activity}

In brief, $50 \mu \mathrm{L}$ samples, $50 \mu \mathrm{L}$ of $0.04 \mathrm{M} \mathrm{Na-phosphate}$ buffer ( $\mathrm{pH} 4.5$ ), and $50 \mu \mathrm{L}$ of $\alpha$-glucosidase were mixed and incubated at $37^{\circ} \mathrm{C}$ for $5 \mathrm{~min}$. The mixture was treated with $50 \mu \mathrm{L}$ of $p$-nitrophenyl- $\alpha$-D-glucopyranoside $(5 \mathrm{mM})$ at $37^{\circ} \mathrm{C}$ for another $5 \mathrm{~min}$. The reaction was terminated using $100 \mu \mathrm{L}$ of $0.2 \mathrm{M} \mathrm{Na}_{2} \mathrm{CO}_{3}$; the absorbance of the reaction mixture was measured at $405 \mathrm{~nm}$ using a microplate spectrophotometer (BioTek Epoch, USA). a-glucosidase inhibitory activity was compared between each sample and the positive control (acarbose).

\subsection{Antimicrobial activity}

The improvement in the intestinal health by oligosaccharide was investigated in the presence of gram-positive bacteria Listeria monocytogenes ATCC 19114 and Staphylococcus aureus ATCC12600, gram-negative bacteria Salmonella typhimurium DT 104, Escherichia coli O157:H7 ATCC 35150, and the cavity-producing bacterium S. mutans KCTC 3065 . The strains were stored at $-80{ }^{\circ} \mathrm{C}$ in stock cultures. Tryptic soy broth (TSB, Difco Laboratories, Detroit, MI, USA) was used in the experiment. The strains in stock cultures were activated by incubating twice at $37^{\circ} \mathrm{C}$ for $18 \mathrm{~h}$ before being used in the test. The inhibitory effects of food-poisoning and cavity-generating bacteria were measured by the paper-disc method described by Ericsson et al. (1960) with minor modifications. The diameter of the inhibition zone produced around the disc was measured after incubation of plates at $37^{\circ} \mathrm{C}$ for $24 \mathrm{~h}$.

\subsection{Statistical analysis}

All experiments were conducted in triplicates, and the results were expressed as mean \pm standard deviation. The data were analyzed using one-way analysis of variance (ANOVA). The means between different groups were compared by the Duncan's multiple-range test using SPSS program (SPSS version 23.0 for windows, SPSS Inc., Chicago, IL, USA). The data on sugar and phenolic contents were assessed using the Student's $t$-test. Values of $p<0.05$ were considered significant.

\section{Results and discussion}

\subsection{Identification of strains}

The 16S rRNA was analyzed by sequencing and PCR to identify the strain NY 518 . NY 518 shared $99 \%$ identity with the $16 \mathrm{~S}$ rRNA sequences of Lactobacillus isolates such as L. casei (D86517), L. zeae (D86516), L. brevis (M58810), L. pentosus (D79211), L. paraplantarum (AJ306297), L. johnsonii (AJ002515), L. acidophilus (M58802), L. amylovorus (M58805), and L.crispatus (Y17362), suggesting that it belongs to the genus Lactobacillus. Phylogenetic analysis of $16 \mathrm{~S}$ rRNA sequences showed that the strain NY 518 and L. sakei were clustered together (Figure 1). Thus, the strain NY 518 was identified as L. sakei.

\subsection{Optimal conditions for oligosaccharide production}

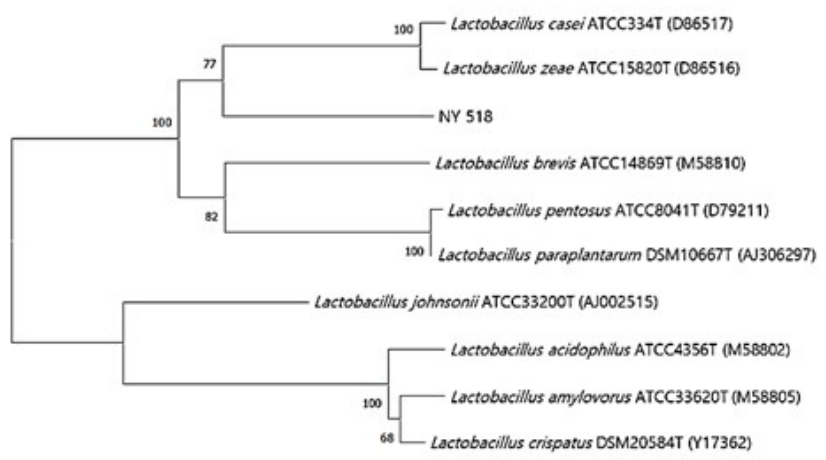

0.010

Figure 1. Phylogenetic tree of the strain NY518. The phylogenetic tree was constructed by the neighbor-joining method. The scale bar equals 0.010 changes per nucleotide position. 
The released fructose content was measured under different substrate concentration, enzyme concentration, and reaction time conditions. Figure 2A, B show the content of the released fructose according to substrate concentrations, revealing $1 \mathrm{M}$ sucrose and $50 \%$ preserved yuzu as optimal concentrations. Figure $2 \mathrm{C}, \mathrm{D}$ indicate the optimal enzyme concentration and reaction time in the presence of $1 \mathrm{M}$ sucrose and 50\% preserved yuzu as substrates. Based on the tendency of released fructose rate, $10 \%$ enzyme and $24 \mathrm{~h}$ reaction time were considered optimal conditions at $1 \mathrm{M}$ sucrose. Also, $10 \%$ enzyme and $48 \mathrm{~h}$ reaction time were optimal conditions to produce oligosaccharide at $50 \%$ preserved yuzu.

Figure 2E shows the results of TLC of oligosaccharides produced under optimal conditions. The synthesis of oligosaccharides was confirmed from sucrose and preserved yuzu. The sugar composition of OY was determined using the method of Kim et al. (2016)
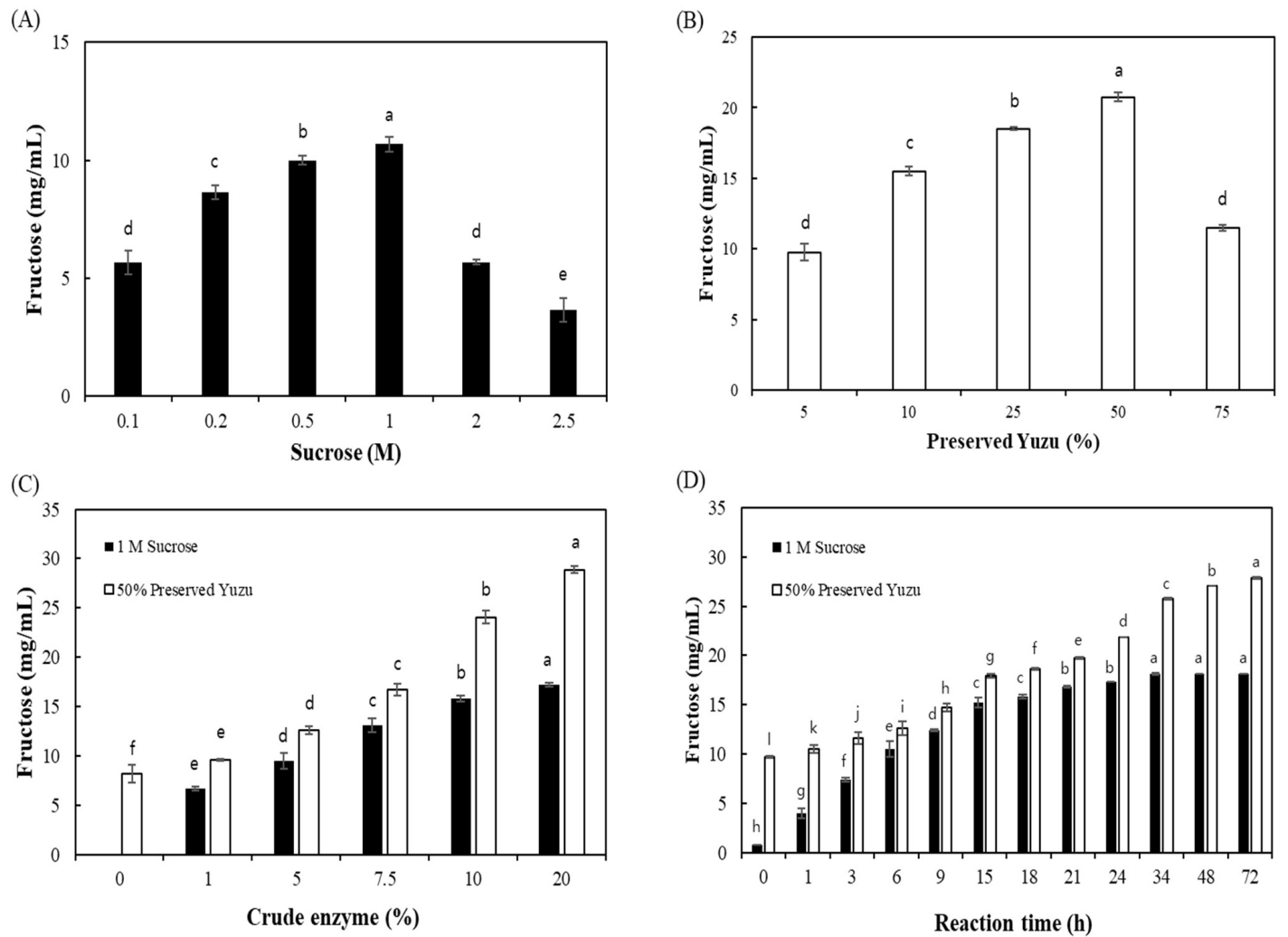

(E)

(F)
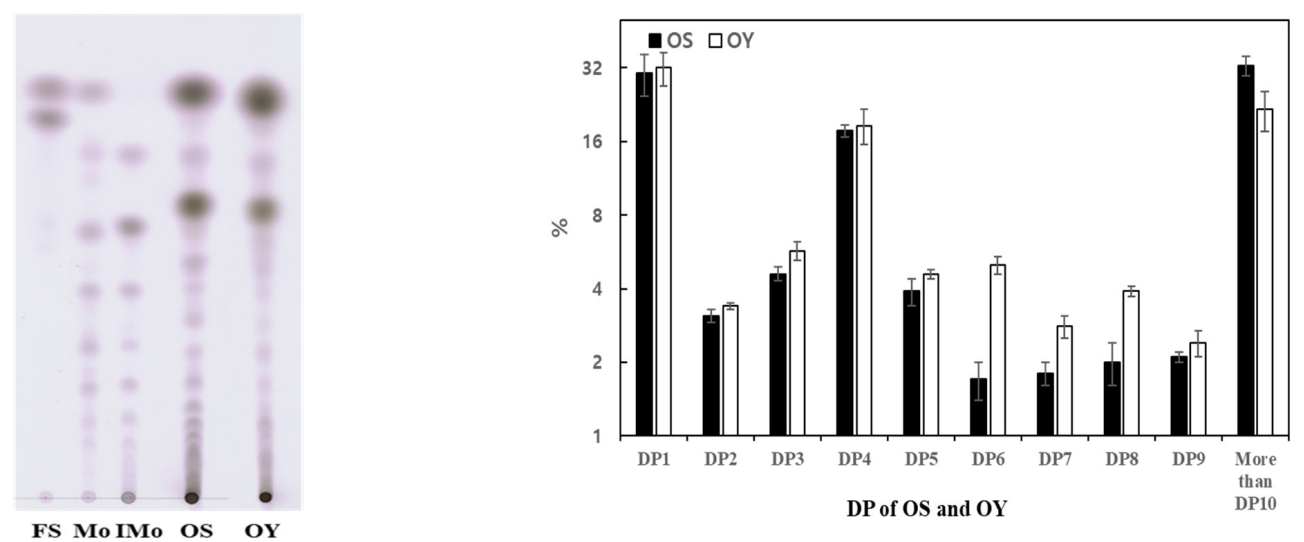

Figure 2. Changes in the released fructose contents based on (A) sucrose concentration, (B) preserved yuzu concentration, (C) crude enzyme concentration, and (D) reaction time. Means with the same letter in each column are not significantly different, as analyzed by the Duncan's multiple range test $(p<0.05)$. 2D-TLC analysis of (E) oligosaccharide from sucrose and (F) oligosaccharide from preserved yuzu. The activity of enzymes produced by L. sakei NY 518 was 10 unit/mL. FS: Fructose-sucrose standards, Mo: Malto-oligosaccharide standard, IMo: Isomaltooligosaccharide standard, OS: Oligosaccharide from sucrose, OY: Oligosaccharide from preserved yuzu. 
based on TLC. OY and oligosaccharide from sucrose (OS) were determined to be homo-oligosaccharides comprising glucose units, as evident from a single glucose spot confirmed through hydrolysis (data not shown). Thus, the enzymes produced by L. sakei NY 518 exhibited dextransucrase activity. To investigate the DP of OY, the intensity of each spot in two-dimensional TLC was quantified (Figure 2F). Both OS and OY showed a sharp rise in the level of monosaccharides, but the content of disaccharides decreased. This observation was attributed to the breakdown of sucrose and release of fructose. Considering that $\mathrm{OY}$ is a homooligosaccharide, it was thought to be composed of glucose units. OY had higher percentages of tri- to nona-saccharides than OS, while OS had higher content of deca-saccharides or higher sugars. Thus, OY is a lower molecular weight oligosaccharide than OS. Sun et al. (2016) found that chitosan oligosaccharide with low molecular weight was effective in allergic asthma. Lee et al. (1998) also reported the low molecular weight alginatemediated physiological improvement in the serum and liver lipid composition. Therefore, low molecular weight oligosaccharides are believed to have different characteristics owing to their high absorption rates in the body. Thus, OY is considered to impart functional properties to yuzu in the form of a low molecular weight oligosaccharide.

\subsection{Physicochemical characteristics}

The changes in the physicochemical properties of substrates and oligosaccharide products are shown in Table 1. As the substrates were converted to oligosaccharides, there was an increase in the measured physicochemical properties except $\mathrm{pH}$ and chromaticity.

Analysis of chromaticity revealed the decrease in the $L$ value and the increase in $\mathrm{a}, \mathrm{b}$, and $\triangle \mathrm{E}$ values after the production of oligosaccharides. This trend was consistent with the report by Cheng et al. (2018), who used enzymes to convert longan juice sugar into oligosaccharides. Preserved yuzu had lower $\mathrm{pH}$ value (3.82) but higher acidity $(1.31 \pm 0.03 \%)$, soluble solids $\left(34.5 \pm 0.00{ }^{\circ} \mathrm{Bx}\right)$, and viscosity than sucrose. Yuzu contains various organic acids such as citric acid, tartaric acid, and ascorbic acid (Yu et al., 2011). Mandadzhieva et al. (2011) reported the use of $L$. sakei S161 in glucose fermentation to produce lactic acid, acetic acid, and ethanol. The low $\mathrm{pH}$ and high acidity of yuzu oligosaccharide was associated with various organic acids in yuzu and the fermentation process.

\subsection{Sugar and phenolic contents}

As preserved yuzu was transformed into oligosaccharides, both the total sugar and reducing sugar contents increased. In particular, there was a significant increase in the content of reducing sugar (Table 2). L. sakei has been known to produce enzymes such as glucansucrase (Kralj et al., 2004) and $\beta$-galactosidase (Iqbal et al., 2011). Glucansucrase hydrolyzes glycosidic bonds of sucrose and catalyzes the synthesis of high molecular weight D-glucose polymers (Monchois et al., 1999), resulting in a change in total sugar and reducing sugar contents. Given that OY is a low molecular weight oligosaccharide (Figure 2F), L. sakei NY 518 produced dextransucrase that participated in hydrolysis and transglucosylation reactions. Both phenolic and flavonoid contents increased in OY. The enzymes produced by L. sakei NY 518 induced hydrolysis of glycosides and produced aglycone in preserved yuzu. However, the levels of some flavonoid family members such as narirutin, naringin, hesperidin, and neohesperidin decreased in OY. Bertrand et al. (2006) reported the successful glycosylation at $\mathrm{C}^{\prime}$ and $\mathrm{C}^{\prime}$ of B-ring in the structure of flavonoids by dextransucrase from L. mesenteroides NRRL B-512F. Thus, this change in phenol and flavonoid components suggests the possibility of hydrolysis and transglucosylation. The contents of narirutin, naringin, hesperidin, and neohesperidin in OY were $34 \%, 44 \%, 26 \%$, and $38 \%$, respectively, lower than those in preserved yuzu. Among flavonoids, naringin and neohesperidin are known to impart a bitter taste (Koca et al., 2009). Naringinase exhibits $\alpha$-rhamnosidase and $\beta$-glucosidase activities (Puri, 2012) and hydrolyzes naringin to naringenin, which is not bitter (Kore et al., 2018). In this experiment, the bitter ingredients decreased; thus, L. sakei NY 518 may produce some $\alpha$-rhamnosidase and $\beta$-glucosidase with activities similar to naringinase activity.

Table 1. Changes in the physicochemical characteristics of oligosaccharides from sucrose and preserved yuzu.

\begin{tabular}{|c|c|c|c|c|c|c|c|}
\hline & \multirow{2}{*}{$\mathrm{pH}$} & \multirow{2}{*}{$\begin{array}{c}\text { Acidity } \\
(\%)\end{array}$} & \multirow{2}{*}{$\begin{array}{c}\text { Soluble solids } \\
\left({ }^{\circ} \text { Brix }\right)\end{array}$} & \multicolumn{4}{|c|}{ Hunter's color value } \\
\hline & & & & $\mathrm{L}$ & $\mathrm{a}$ & $\mathrm{b}$ & $\triangle \mathrm{E}$ \\
\hline Sucrose & $5.37 \pm 0.00^{\mathrm{a} 1)}$ & $0.08 \pm 0.00^{\mathrm{d}}$ & $31.8 \pm 0.00^{\mathrm{d}}$ & $68.04 \pm 0.69^{\mathrm{a}}$ & $-0.62 \pm 0.02^{c}$ & $4.55 \pm 0.10^{\mathrm{d}}$ & $26.67 \pm 0.69$ \\
\hline OS & $5.00 \pm 0.00^{\mathrm{b}}$ & $0.63 \pm 0.01^{\mathrm{c}}$ & $34.0 \pm 0.00^{c}$ & $67.88 \pm 0.66^{\mathrm{a}}$ & $-0.86 \pm 0.02^{\mathrm{d}}$ & $7.58 \pm 0.02^{c}$ & $27.06 \pm 0.05$ \\
\hline Preserved Yuzu & $3.82 \pm 0.00^{c}$ & $1.31 \pm 0.03^{\mathrm{b}}$ & $34.5 \pm 0.00^{\mathrm{b}}$ & $34.89 \pm 0.03^{\mathrm{b}}$ & $0.15 \pm 0.03^{\mathrm{b}}$ & $31.76 \pm 0.06^{\mathrm{b}}$ & $65.90 \pm 0.05^{t}$ \\
\hline OY & $3.73 \pm 0.00^{\mathrm{d}}$ & $1.39 \pm 0.02^{\mathrm{a}}$ & $36.3 \pm 0.25^{\mathrm{a}}$ & $26.44 \pm 0.04^{c}$ & $11.41 \pm 0.01^{\mathrm{a}}$ & $38.42 \pm 0.12^{\mathrm{a}}$ & $77.31 \pm 0.09^{\circ}$ \\
\hline
\end{tabular}

${ }^{1)}$ Means with the same letter in each column are not significantly different, as analyzed by the Duncan's multiple range test ( $\left.p<0.05\right)$. The values represent the mean $\pm \mathrm{SD}(\mathrm{n}=3)$. OS: Oligosaccharide from sucrose; OY: Oligosaccharide from preserved yuzu. $\Delta \mathrm{E}$ (color difference) is calculated by terms of $\mathrm{L}($ lightness), a(redness), $\mathrm{b}(\mathrm{yellowness})$ as $\Delta \mathrm{E}=\sqrt{ }(\Delta L 2+\Delta a 2+\Delta b 2)$.

Table 2. Changes in sugar and phenolic contents of oligosaccharides from preserved yuzu.

\begin{tabular}{ccccccc}
\hline & $\begin{array}{c}\text { Total sugar } \\
(\mathrm{mg} / \mathrm{mL})\end{array}$ & $\begin{array}{c}\text { Reducing sugar } \\
(\mathrm{mg} / \mathrm{mL})\end{array}$ & $\begin{array}{c}\text { Narirutin } \\
(\mathrm{mg} / 100 \mathrm{~g})\end{array}$ & $\begin{array}{c}\text { Naringin } \\
(\mathrm{mg} / 100 \mathrm{~g})\end{array}$ & $\begin{array}{c}\text { Hesperidin } \\
(\mathrm{mg} / 100 \mathrm{~g})\end{array}$ & $\begin{array}{c}\text { Neohesperidin } \\
(\mathrm{mg} / 100 \mathrm{~g})\end{array}$ \\
\hline Preserved Yuzu & $762.29 \pm 3.76$ & $90.53 \pm 0.62^{\mathrm{b}}$ & $235.66 \pm 0.20^{\mathrm{a}}$ & $62.47 \pm 0.08^{\mathrm{a}}$ & $149.73 \pm 0.03^{\mathrm{a}}$ & $65.82 \pm 0.01^{\mathrm{a}}$ \\
OY & $783.55 \pm 55.63$ & $765.8 \pm 3.28^{\mathrm{a}}$ & $157.34 \pm 0.11^{\mathrm{b}}$ & $35.03 \pm 0.03^{\mathrm{b}}$ & $112.43 \pm 0.05^{\mathrm{b}}$ & $41.33 \pm 0.14^{\mathrm{b}}$ \\
\hline
\end{tabular}

${ }^{1)}$ Means with the same letter in each column are not significantly different, as analyzed by the Student's $t$-test $(p<0.05)$. The values represent mean \pm SD. OY: Oligosaccharide from preserved yuzu. 


\section{$3.5 \alpha$-glucosidase inhibitory activity}

The a-glucosidase inhibitory activity was investigated to determine the antidiabetic effect of OS and OY. As shown in Figure 3, OS and OY exhibited seven and two times higher a-glucosidase inhibitory activities, respectively, than their substrates. Oligosaccharides are known to prevent diabetes by inhibiting a-glucosidase and relieving insulin and leptin resistance (Zhu et al., 2019), but the exact mechanism is yet unclear. As the inhibitory activity of $a$-glucosidase decreases with a decrease in the viscosity of polysaccharides (Yuan et al., 2020), the increased $\alpha$-glucosidase inhibition activity was related to the viscosity of the produced oligosaccharides. As the viscosity of OS was lower than that of OY (Table 1), factors other than viscosity may influence the a-glucosidase inhibition activity. Therefore, OY had some active inhibitors of $\alpha$-glucosidase that could mediate anti-diabetic effect.

\subsection{Antimicrobial activity}

The antibacterial activities of OS and OY were investigated through the agar diffusion assay using five food-poisoning or cavity-producing strains (Figure 4).

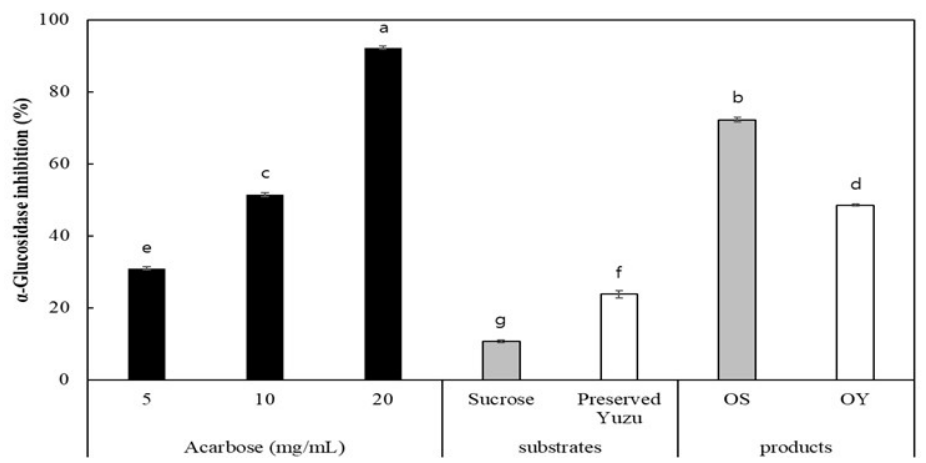

Figure 3. $\alpha$-glucosidase inhibition activities of oligosaccharides from sucrose and preserved yuzu. Means with the same letter in each column are not significantly different, as analyzed by the Duncan's multiple range test $(p<0.05)$. OS: Oligosaccharide from sucrose, OY: Oligosaccharide from preserved yuzu.

(A)

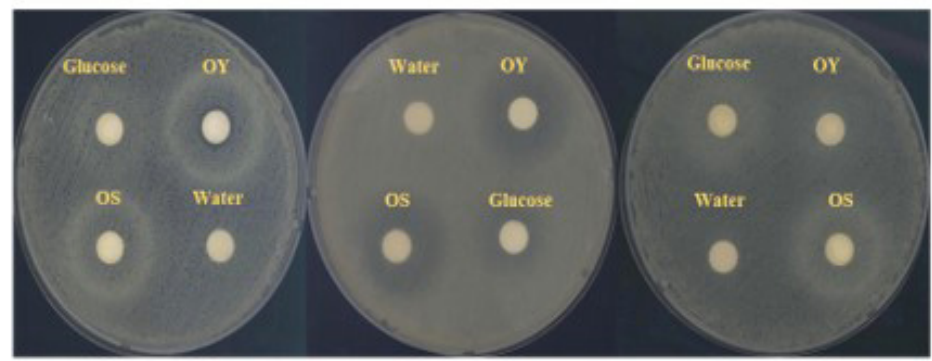

S. aureus

S. typhimurium

E. coli $0157: \mathrm{H} 7$

(B)

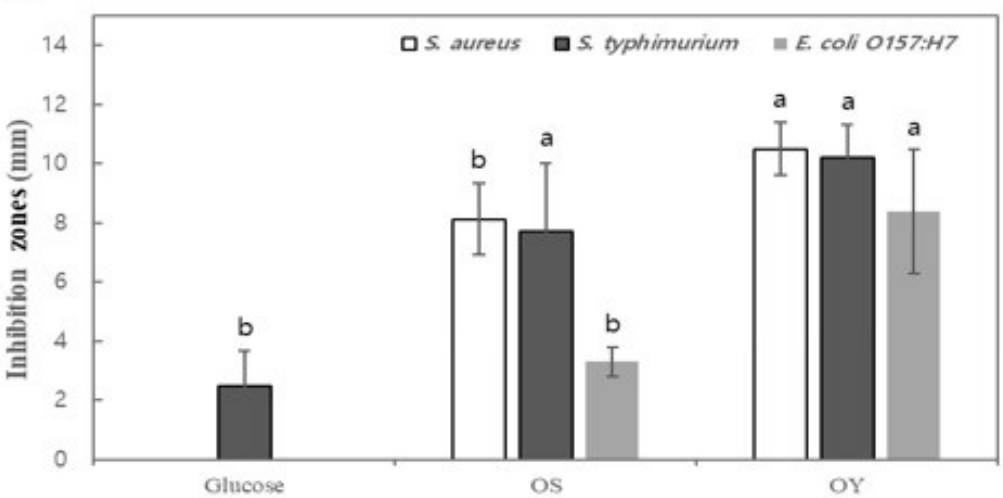

Figure 4. Antimicrobial activities of oligosaccharides. (A) Antimicrobial activity on agar plate against Staphylococcus aureus ATCC 12600, Salmonella typhimurium DT104, and Escherichia coli O157:H7 ATCC 35150. (B) Measurement of inhibition zones. Means with the same letter in each column are not significantly different, as analyzed by the Duncan's multiple range test $(p<0.05)$. 
Both OS and OY exhibited antibacterial activities against $S$. aureus ATCC 12600, Salmonella typhimurium DT104, and E. coli O157:H7 ATCC 35150 but not against L. monocytogenes ATCC 19114 and S. mutans KCTC 3065. The antibacterial activity of YS was higher than that of OS, especially against $S$. aureus ATCC 12600 and Salmonella typhimurium DT104 (10.5 \pm 0.9 and $10.2 \pm 1.1 \mathrm{mM}$ zone of inhibition, respectively). In addition, OY showed an $8.37 \mathrm{mM}$ zone of inhibition for E. coli $\mathrm{O} 157: \mathrm{H} 7$, indicating 2.5 time's higher antibacterial activity than that of OS at the same concentration. Glucose showed antibacterial activity only against Salmonella typhimurium DT104, while OS was found to be more effective against gram-positive and oral odor-producing strains than against gram-negative bacteria. Polysaccharides composed of many monosaccharides linked by glycosidic bonds are known to exert antibacterial activity, and the underlying mechanism has been associated with their molecular weights (No et al., 2002; Simůnek et al., 2012). In this experiment, the increase in the antibacterial activity of OS and OY was thought to be related to the change in their molecular weights, as OS showed higher antibacterial activity against Salmonella typhimurium DT104 than glucose.

\section{Conclusion}

In conclusion, the strain NY 518 considered to produce oligosaccharide was isolated from traditional foods and identified as $L$. sakei. The oligosaccharide produced by enzymatic reactions was a gluco-oligosaccharide. OY had higher percentages of tri- to nona-saccharides than OS. The bioconversion from preserved yuzu to oligosaccharide reduced its $\mathrm{pH}$ and increased the acidity. The levels of some flavonoid family members such as narirutin, naringin, hesperidin, and neohesperidin decreased. In addition, OY showed higher $\alpha$-glucosidase inhibition activity as well as phenolic compounds and superior antimicrobial effects than OS. L. sakei NY 518 could be used as a low molecular weight oligosaccharide-producing strain and applied to sugar-preserved foods. The produced oligosaccharide had better functions than conventional oligosaccharides.

\section{Acknowledgements}

This study was supported by Korea Institute of Planning and Evaluation for Technology in Food, Agriculture and Forestry (319089-03-1-HD030) and by Rural Development Administration (Project No. PJ01576620)

\section{References}

Abrahim, A., Al-Sayah, M., Skrdla, P., Bereznitski, Y., Chen, Y., \& Wu, N. (2010). Practical comparison of 2.7 microm fused-core silica particles and porous sub-2 microm particles for fast separations in pharmaceutical process development. Journal of Pharmaceutical and Biomedical Analysis, 51(1), 131-137. http://dx.doi.org/10.1016/j. jpba.2009.08.023. PMid:19758782.

Azevedo, P. F., Chaddad, F. R., \& Farina, E. M. (2004). The food industry in Brazil and the United States: the effects of the FTAA on trade and investment. Buenos Aires: IDB-INTAL.

Bae, M. J., \& Yoo, S. H. (2019). Changes in oligosaccharide content during the storage period of maesil cheong formulated with functional oligosaccharides. Korean Journal of Food Science Technology, 51(2), 169-175.

Bertrand, A., Morel, S., Lefoulon, F., Rolland, Y., Monsan, P., \& RemaudSimeon, M. (2006). Leuconostoc mesenteroides glucansucrase synthesis of flavonoid glucosides by acceptor reactions in aqueousorganic solvents. Carbohydrate Research, 341(7), 855-863. http:// dx.doi.org/10.1016/j.carres.2006.02.008. PMid:16530175.

Chen, G., Fang, C., Ran, C., Tan, Y., Yu, Q., \& Kan, J. (2019). Comparison of different extraction methods for polysaccharides from bamboo shoots (Chimonobambusa quadrangularis) processing byproducts. International Journal of Biological Macromolecules, 130, 903-914. http://dx.doi.org/10.1016/j.ijbiomac.2019.03.038. PMid:30849468.

Cheng, Y., Lan, H., Zhao, L., Wang, K., \& Hu, Z. (2018). Characterization and prebiotic potential of longan juice obtained by enzymatic conversion of constituent sucrose into fructo-oligosaccharides. Molecules, 23(10), 2596. http://dx.doi.org/10.3390/molecules23102596. PMid:30309034.

Chuang, W. L., Christ, M. D., \& Rabenstein, D. L. (2001). Determination of the primary structures of heparin-and heparan sulfate-derived oligosaccharides using band-selective homonuclear-decoupled twodimensional 1H NMR experiments. Analytical Chemistry, 73(10), 2310-2316. http://dx.doi.org/10.1021/ac0100291. PMid:11393857.

Doner, L. W., \& Irwin, P. L. (1992). Assay of reducing end-groups in oligosaccharide homologues with 2, 2'-bicinchoninate. Analytical Biochemistry, 202(1), 50-53. http://dx.doi.org/10.1016/00032697(92)90204-K. PMid:1320350.

Ericsson, H., Tunevall, G., \& Wickman, K. (1960). The paper disc method for determination of bacterial sensitivity to antibiotics: Relationship between the diameter of the zone of inhibition and the minimum inhibitory concentration. Scandinavian Journal of Clinical and Laboratory Investigation, 12(4), 414-422. http://dx.doi. org/10.3109/00365516009065406. PMid:13697132.

Formagio, A. S., Kassuya, C. A., Formagio, F. No., Volobuff, C. R., Iriguchi, E. K., Vieira, M. C., \& Foglio, M. A. (2013). The flavonoid content and antiproliferative, hypoglycaemic, anti-inflammatory and free radical scavenging activities of Annona dioica St. Hill. BMC Complementary and Alternative Medicine, 13(1), 14. http://dx.doi. org/10.1186/1472-6882-13-14. PMid:23311341.

Ghebregzabher, M., Rufini, S., Monaldi, B., \& Lato, M. (1976). Thinlayer chromatography of carbohydrates. Journal of Chromatography, 127(2), 133-162. http://dx.doi.org/10.1016/S0021-9673(00)80168-5. PMid:184106.

Gibson, G. R., Hutkins, R., Sanders, M. E., Prescott, S. L., Reimer, R. A., Salminen, S. J., Scott, K., Stanton, C., Swanson, K. S., Cani, P. D., Verbeke, K., \& Reid, G. (2017). Expert consensus document: the International Scientific Association for Probiotics and Prebiotics (ISAPP) consensus statement on the definition and scope of prebiotics. Nature Reviews. Gastroenterology \& Hepatology, 14(8), 491-502. http://dx.doi.org/10.1038/nrgastro.2017.75. PMid:28611480.

Huh, K. T. (1995). The physiological function characteristics of oligosaccharide: especially galactooligo sugar. Food Science and Industry, 28, 24-28.

Iqbal, S., Nguyen, T. H., Nguyen, H. A., Nguyen, T. T., Maischberger, T., Kittl, R., \& Haltrich, D. (2011). Characterization of a heterodimeric GH2 $\beta$-galactosidase from Lactobacillus sakei Lb790 and formation of prebiotic galacto-oligosaccharides. Journal of Agricultural and Food Chemistry, 59(8), 3803-3811. http://dx.doi.org/10.1021/jf103832q. PMid:21405014.

Jung, K. M., Choi, M., \& Park, S. I. (2017). Effect of oligosaccharides on quality characteristics and antioxidant activities of Prunus persica Batsch. var. davidiana. Max. preserved in sugar. Culinary Science 
and Hospitality Research, 23(8), 163-172. http://dx.doi.org/10.20878/ cshr.2017.23.8.016.

Kim, D. S., Kim, D. H., Oh, M. J., Lee, K. G., Kook, M. C., \& Park, C. S. (2010). Antiaging and whitening activities of ethanol extract of Yuza (Citrus junos SIEB ex TANAKA) by-product. Journal of the Society of Cosmetic Scientists of Korea, 36(2), 137-143.

Kim, Y. H., Kim, S. B., Kim, S. J., \& Park, S. W. (2016). Market and trend of alternative sweeteners. Food Science and Industry, 49(3), 17-28.

Koca, U., Berhow, M. A., Febres, V. J., Champ, K. I., Carrillo-Mendoza, O., \& Moore, G. A. (2009). Decreasing unpalatable flavonoid components in Citrus: the effect of transformation construct. Physiologia Plantarum, 137(2), 101-114. http://dx.doi.org/10.1111/ j.1399-3054.2009.01264.x. PMid:19656329.

Kore, V. T., Tawade, S. S., Devi, L. H., \& Chakraborty, I. (2018). Use of pre and post harvest low cost techniques to control/minimize citrus juice bitterness. Am. Res. J. Food Nutr, 1, 11-21.

Kralj, S., van Geel-Schutten, G. H., Dondorff, M. M. G., Kirsanovs, S., van der Maarel, M. J. E. C., \& Dijkhuizen, L. (2004). Glucan synthesis in the genus Lactobacillus: isolation and characterization of glucansucrase genes, enzymes and glucan products from six different strains. Microbiology, 150(11), 3681-3690. http://dx.doi. org/10.1099/mic.0.27321-0. PMid:15528655.

Lee, D. S., Nam, T. J., \& Pyeun, J. H. (1998). Effect of low molecular alginates on cholesterol levels and fatty acid compositions of serum and liver lipids in cholesterol-fed rats. Korean Journal of Fisheries and Aquatic Sciences, 31(3), 399-408.

Liu, Y., \& Li, S. M. (2020). Extraction optimization and antioxidant activity of Phyllanthus urinaria polysaccharides. Food Science and Technology, 41(Suppl. 1), 91-97. http://dx.doi.org/10.1590/fst.11320.

Mandadzhieva, T., Ignatova-Ivanova, T., Kambarev, S., Iliev, I., \& Ivanova, I. (2011). Utilization of different prebiotics by Lactobacillus Spp and Lactococcus Spp. Biotechnology, Biotechnological Equipment, 25(Suppl. 1), 117-120. http://dx.doi.org/10.5504/BBEQ.2011.0132.

Monchois, V., Willemot, R. M., \& Monsan, P. (1999). Glucansucrases: mechanism of action and structure-function relationships. FEMS Microbiology Reviews, 23(2), 131-151. http://dx.doi.org/10.1016/ S0168-6445(98)00041-2. PMid:10234842.

No, H. K., Park, N. Y., Lee, S. H., \& Meyers, S. P. (2002). Antibacterial activity of chitosans and chitosan oligomers with different molecular weights. International Journal of Food Microbiology, 74(1-2), 65-72. http://dx.doi.org/10.1016/S0168-1605(01)00717-6. PMid:11929171.

Park, H. Y., Choi, H. D., \& Kim, Y. (2016). Research trend in sugar alternatives. Food Science and Industry, 49(3), 40-54.

Puri, M. (2012). Updates on naringinase: structural and biotechnological aspects. Applied Microbiology and Biotechnology, 93(1), 49-60. http:// dx.doi.org/10.1007/s00253-011-3679-3. PMid:22080346.

Rao, P., \& Pattabiraman, T. N. (1989). Reevaluation of the phenolsulfuric acid reaction for the estimation of hexoses and pentoses. Analytical Biochemistry, 181(1), 18-22. http://dx.doi.org/10.1016/00032697(89)90387-4. PMid:2817377.

Simůnek, J., Brandysová, V., Koppová, I., \& Simůnek, J. Jr. (2012). The antimicrobial action of chitosan, low molar mass chitosan, and chitooligosaccharides on human colonic bacteria. Folia Microbiologica, 57(4), 341-345. http://dx.doi.org/10.1007/s12223-012-0138-1. PMid:22528310.

Sun, X., Lin, L., Liu, X., Zhang, F., Chi, L., Xia, Q., \& Linhardt, R. J. (2016). Capillary electrophoresis-mass spectrometry for the analysis of heparin oligosaccharides and low molecular weight heparin. Analytical Chemistry, 88(3), 1937-1943. http://dx.doi.org/10.1021/ acs.analchem.5b04405. PMid:26714061.

Yu, H. Y., Park, S. W., Chung, I. M., \& Jung, Y. S. (2011). Anti-platelet effects of yuzu extract and its component. Food and Chemical Toxicology, 49(12), 3018-3024. http://dx.doi.org/10.1016/j.fct.2011.09.038. PMid:22005257.

Yuan, D., Li, C., You, L., Dong, H., \& Fu, X. (2020). Changes of digestive and fermentation properties of Sargassum pallidum polysaccharide after ultrasonic degradation and its impacts on gut microbiota. International Journal of Biological Macromolecules, 164, 1443-1450. http://dx.doi.org/10.1016/j.ijbiomac.2020.07.198. PMid:32735930.

Zhao, J. L., Zhang, M., \& Zhou, H. L. (2019). Microwave-assisted extraction, purification, partial characterization, and bioactivity of polysaccharides from panax ginseng. Molecules, 24(8), 1605-1622. http://dx.doi.org/10.3390/molecules24081605. PMid:31018583.

Zhu, D., Yan, Q., Liu, J., Wu, X., \& Jiang, Z. (2019). Can functional oligosaccharides reduce the risk of diabetes mellitus? The FASEB Journal, 33(11), 11655-11667. http://dx.doi.org/10.1096/fj.201802802RRR. PMid:31415188. 